\title{
Electrokinetic Stabilization of Soft Clay
}

\author{
Mona Malekzadeh ${ }^{\mathrm{a}}$ and Zalihe Nalbantoglu \\ Department of Civil Engineering, Eastern Mediterranean University/Gazimagusa, Mersin \\ 10, Turkey.
}

amona.malekzadeh@cc.emu.edu.tr

\begin{abstract}
Electrokinetic is the movement of ions, charged solid particles and water between two electrodes under the influence of an electrical field. Electrokinetic can be applied to the fields such as stabilization of soft soils and slopes, decontamination of pollutants, and sealing and leak-detection system of geomembrane, etc. The aim of this study was to evaluate the use of electrokinetic as an effective method to strengthen the soft clay soil with high compressibility. An in situ soil treatment technique using the principles of electrokinetic was tested using laboratory experimental models. The effectiveness of this approach in stabilizing and improving the physical properties of soft clay was tested and examined. In the study, soil specimens were compacted in glass tanks to reproduce in-situ density and in-situ water content. Mild steel electrodes were inserted into the soil and a direct current was passed through the soil under a constant potential gradient of 35-60 Volts for a period of 14 days. Distilled water and saturated lime solutions were introduced to the soil from anode to cathodes over the testing period. The physical and index properties of the soft clay were tested before and after the electrokinetics stabilization and the results were discussed. Test results indicated that introducing lime into the soil by electrokinetic method reduced the plasticity index of the soil and resulted in a lower compressibility of the soft clay. Treatment of soil by electrokinetic method enabled the measurement of the compressive strength of the soil which resulted in an increase in soil's strength.
\end{abstract}

Keywords: Compressibility, Electrokinetics, Lime, Soil stabilization. 